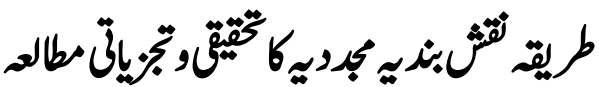

\section{Research and Analytical Study of Naqshbandiya Mujaddidiya Method}

Muhammad Qasim*

Prof Dr. Matloob Ahmad**

\section{Abstract}

Various elders have determined the various ways to attain nearness to God and knowledge of God through their experiences. They are called methods. In this way, innumerable ways to reach Allah Almighty are revealed. But the Almighty has, through His knowledge, devoted himself to following the religion of Islam, the path chosen by the Holy Prophets, the truthful and the martyrs, the righteous. Therefore, the millions of saints and the great mystics have taken the various paths of divine knowledge. They seem to be separate. But they all have the same destination. Whichever path the seeker takes, one day he will reach his destination. The goal is to bring everyone closer to God.

Keywords: Research Study, Analytical, Method, Naqshbandiya Mujaddidiya.

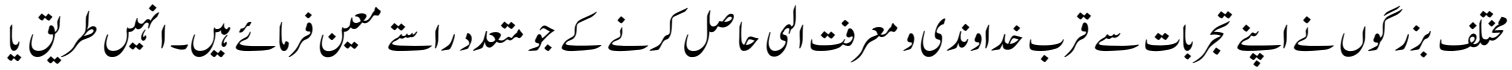

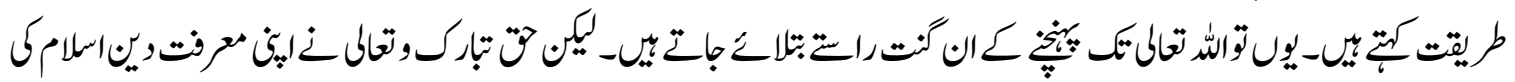

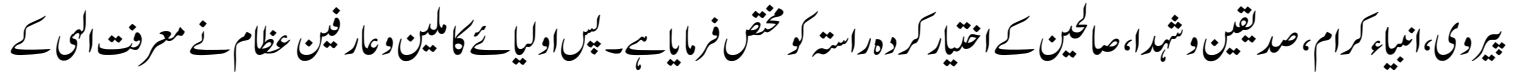

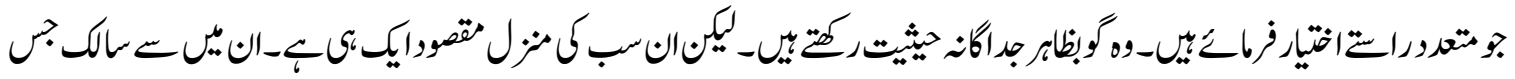

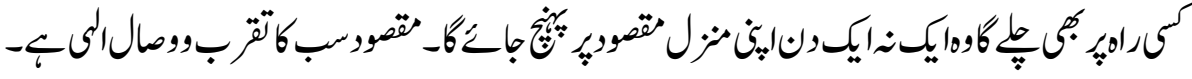

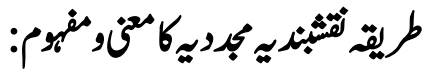

$$
\begin{aligned}
& \text { : } 1
\end{aligned}
$$

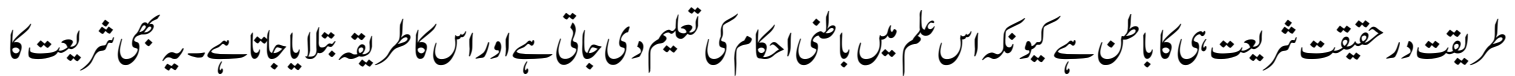

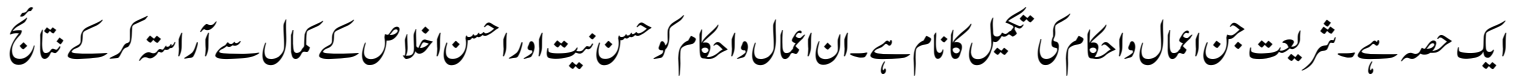

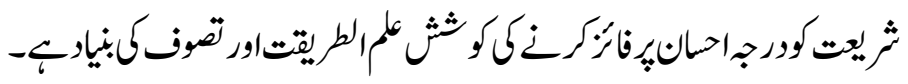

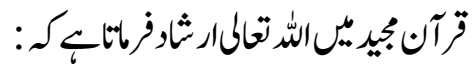

$$
\begin{aligned}
& \text { "يّايها الذين امنوا اتقوا الله وابتغوا اليه الوسيلة"1 }
\end{aligned}
$$

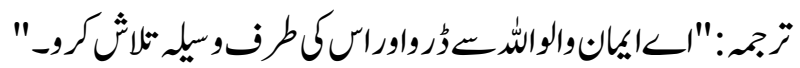

* Ph.D Research Scholar, The University of Faisalabad.

Email: qasim.vumcs@gmail.com,m.qasim2937@gmail.com

${ }^{* *}$ Chairman, Department of Arabic And Islamic Studies, The University of Faisalabad. 


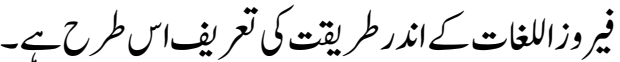

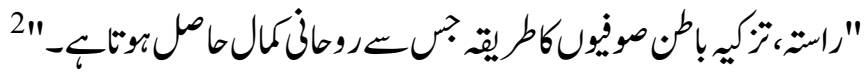

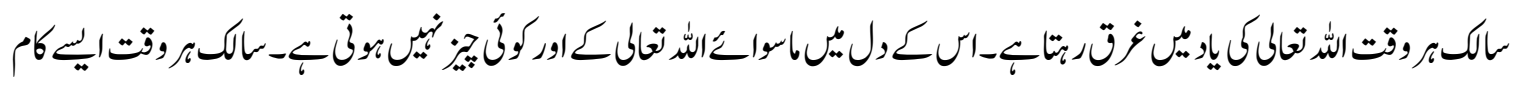

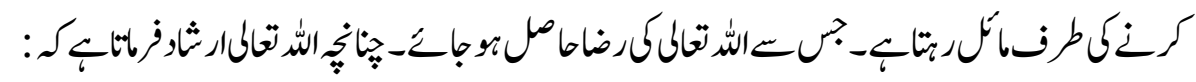

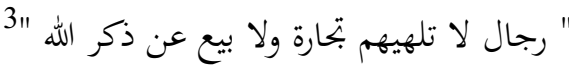

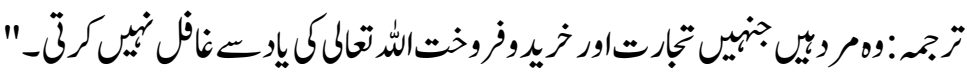

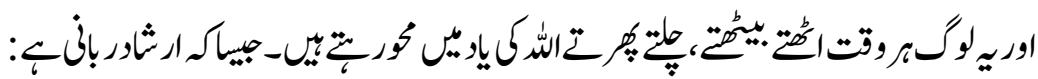

" واذكر ربك في نفسك" 4

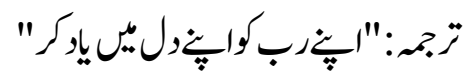

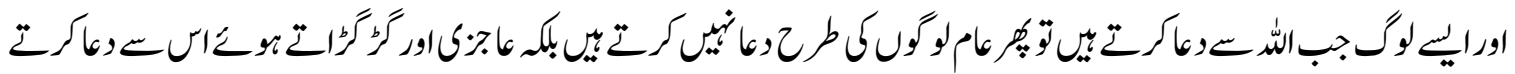

$$
\begin{aligned}
& \text { " ادعوا ربكم تضرعا وخفية" } 5
\end{aligned}
$$

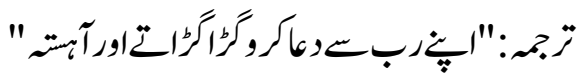

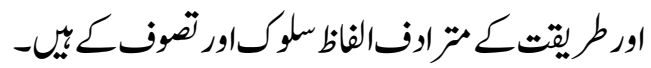

$$
\begin{aligned}
& \text { " وأن لو استقاموا على الطريقة" } 6
\end{aligned}
$$

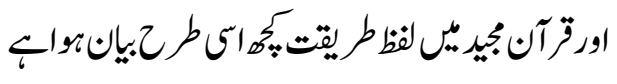

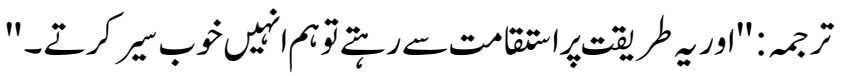

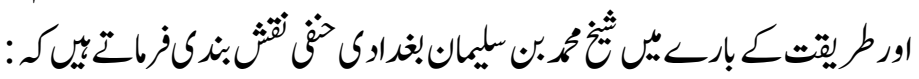

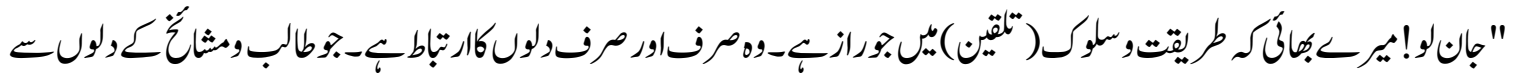

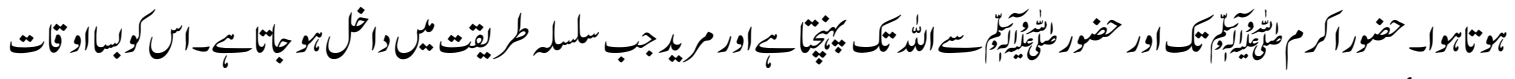

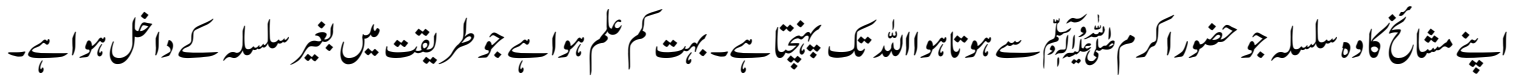

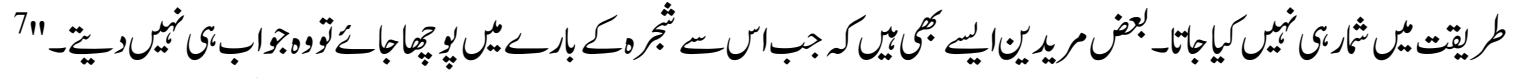

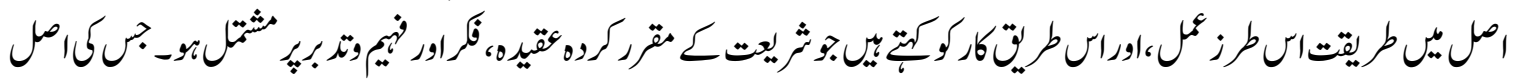

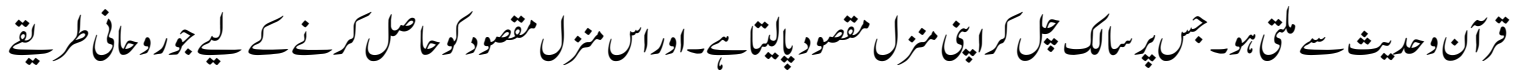

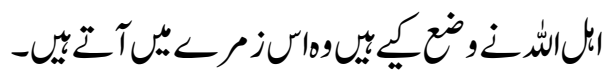




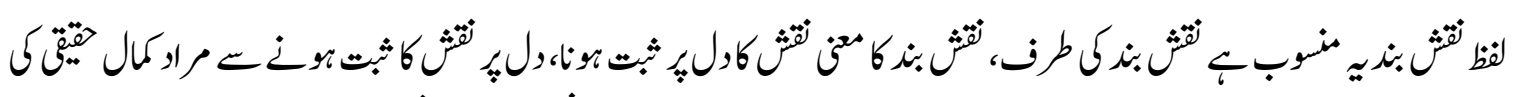

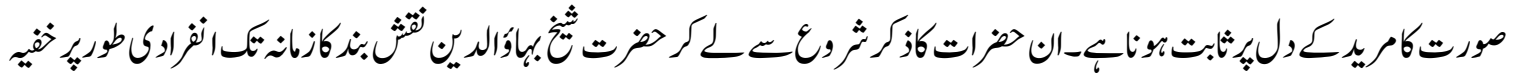

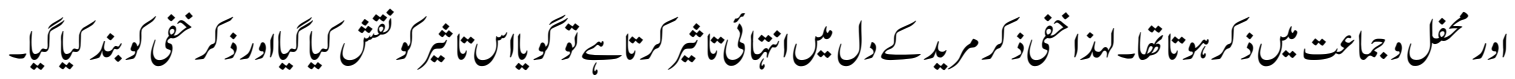

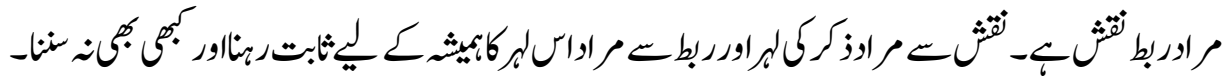

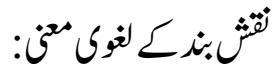

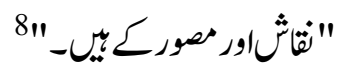

3. مبر:

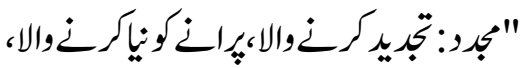

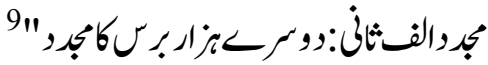

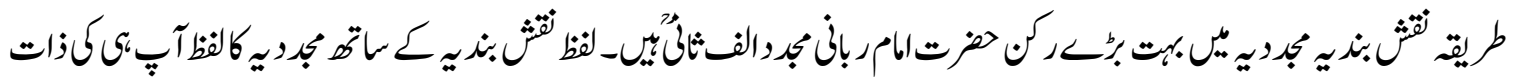

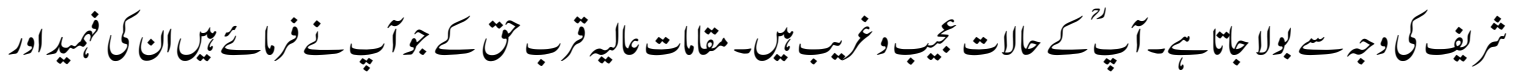

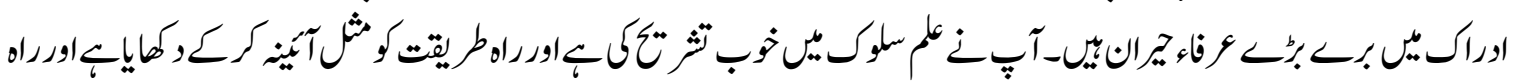

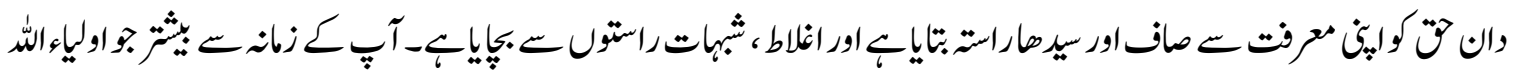

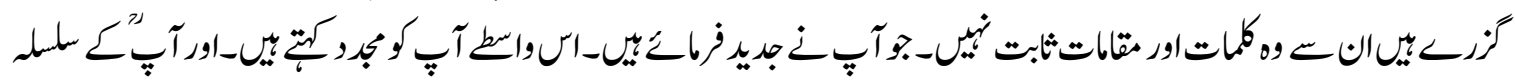
مريقت كومبرديمباجابتاب

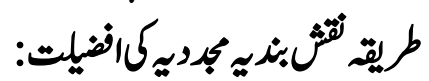

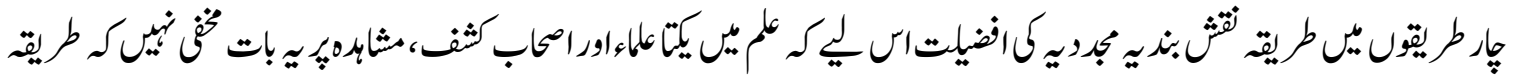

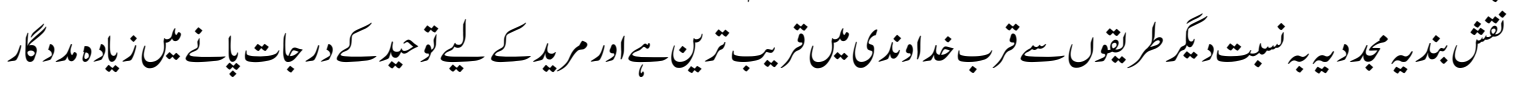

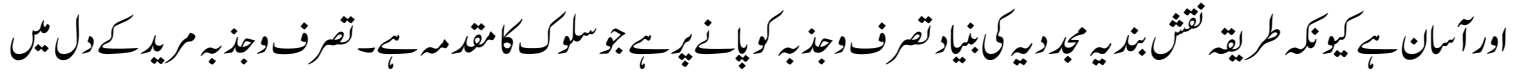

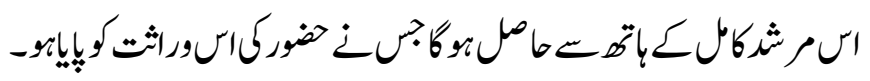

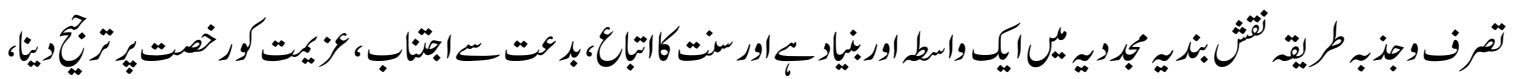

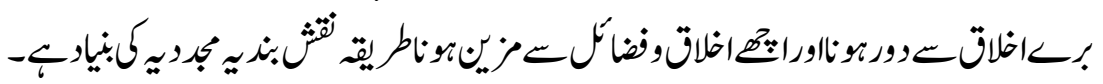

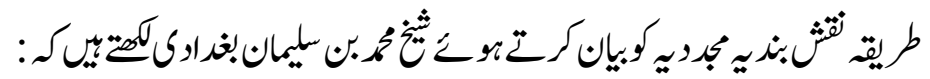

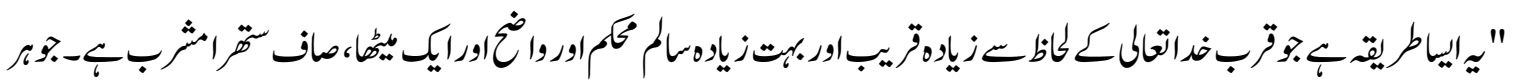

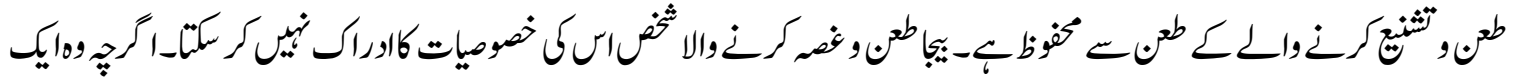

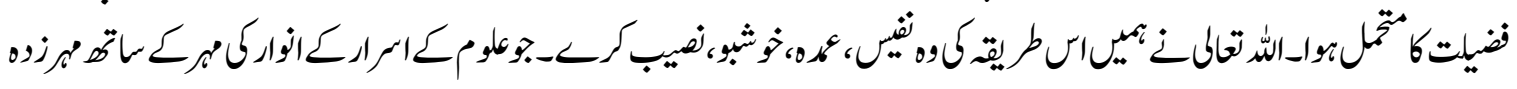




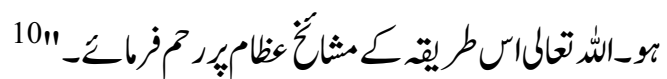

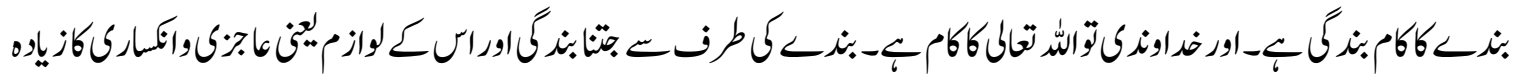

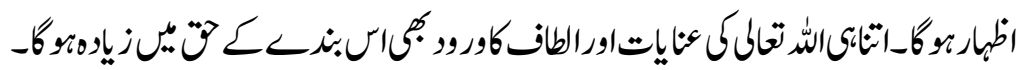

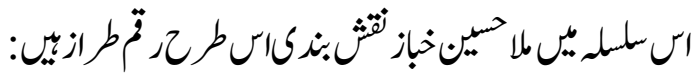

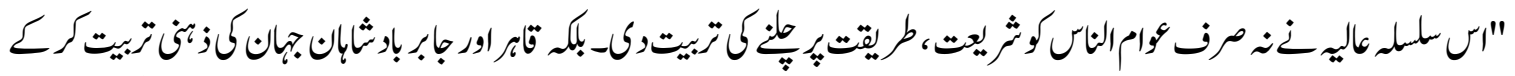

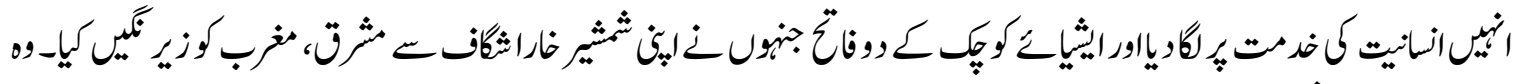

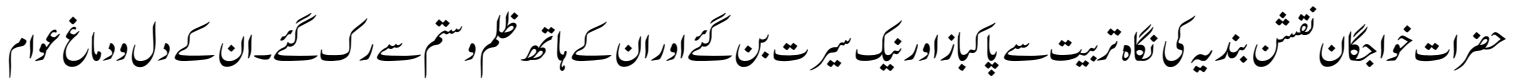

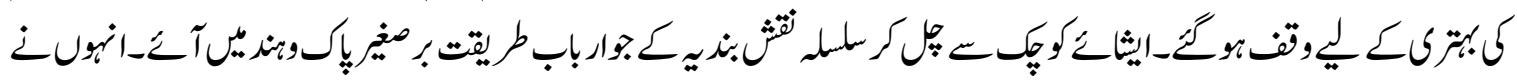

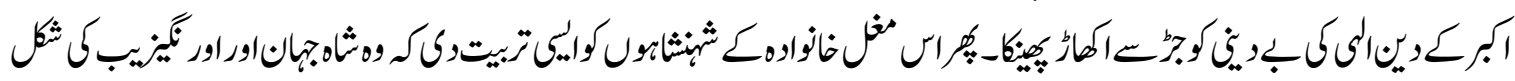

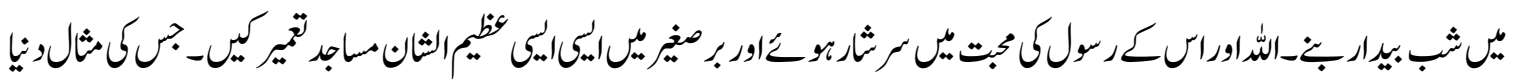

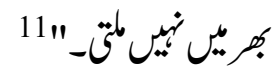

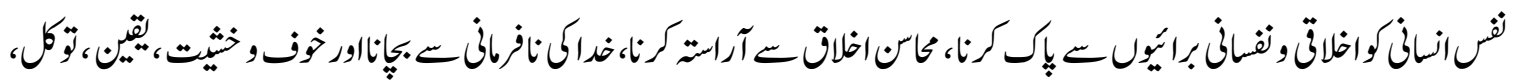

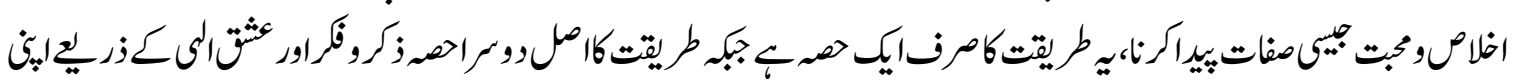

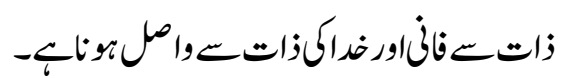

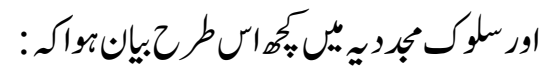

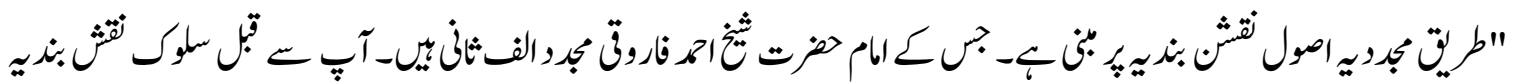

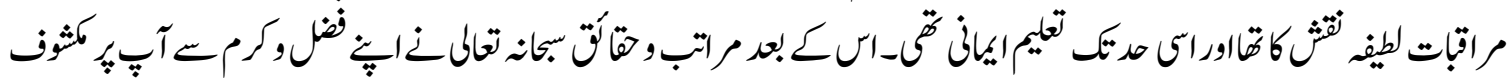

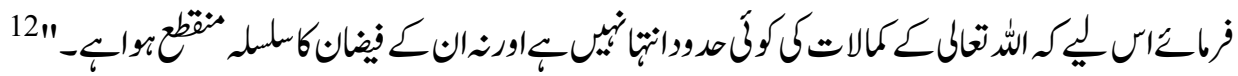

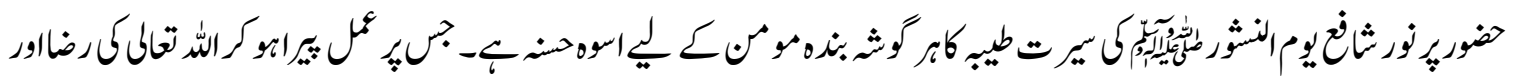

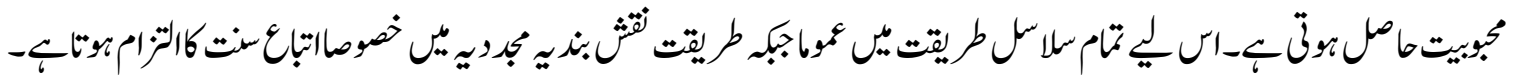

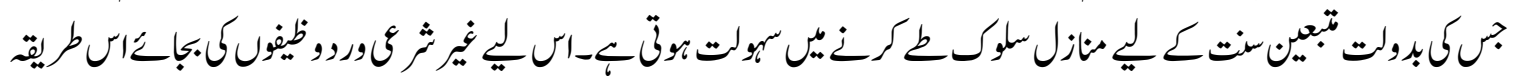

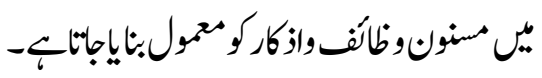

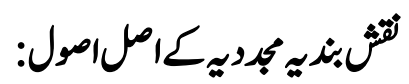

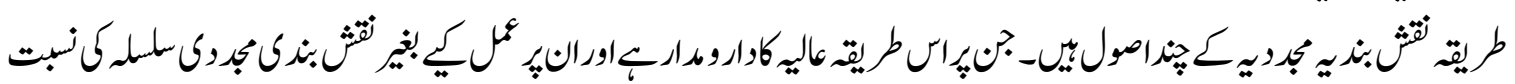

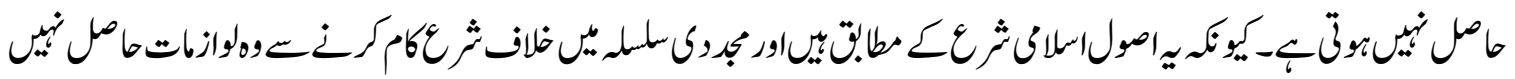

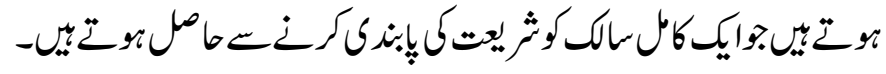




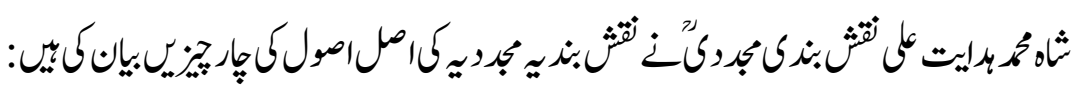
"

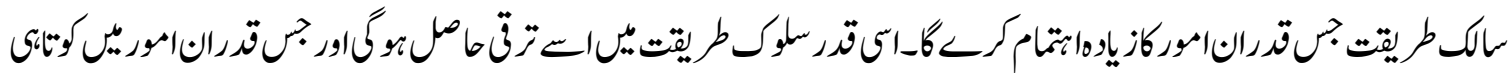

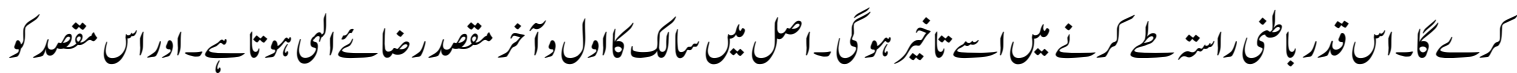

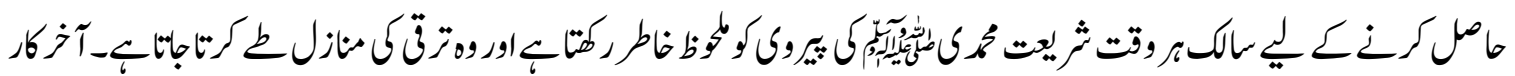

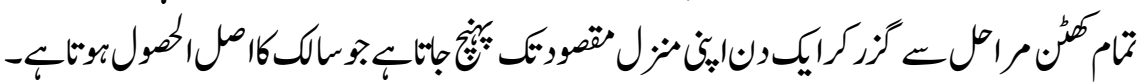

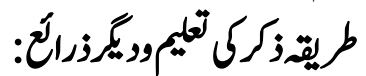

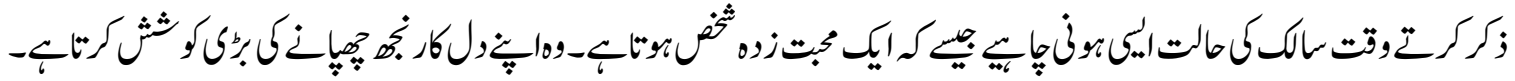

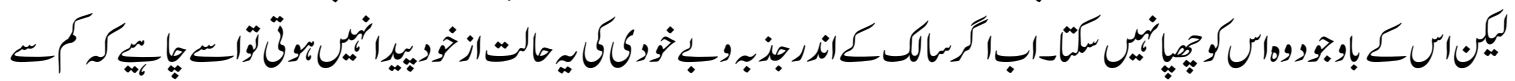

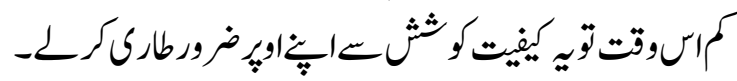

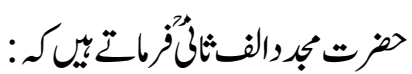

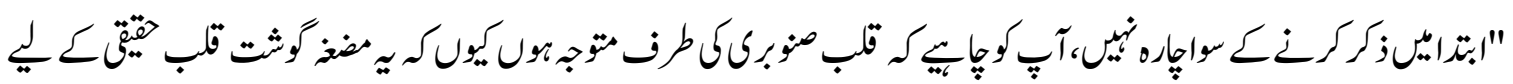

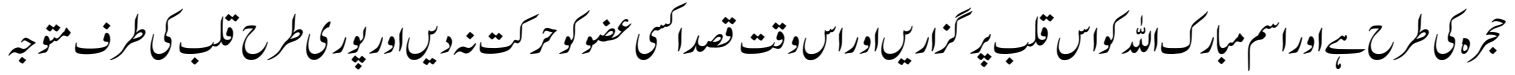

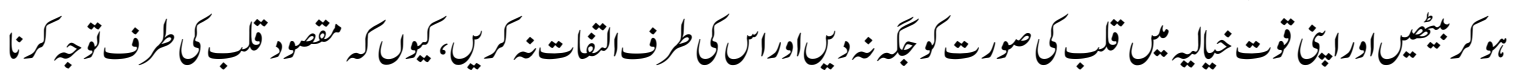

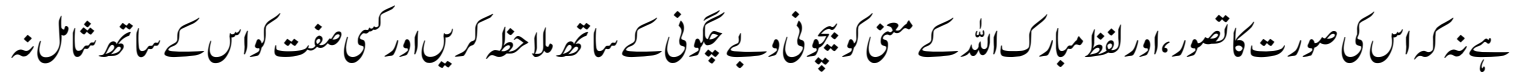

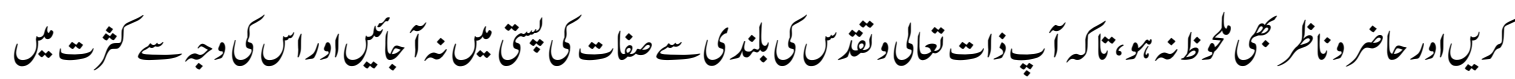

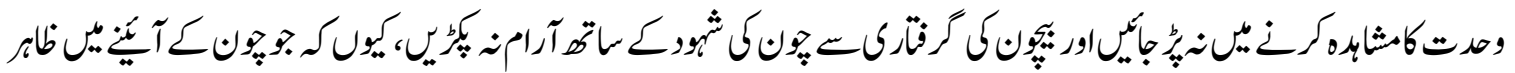

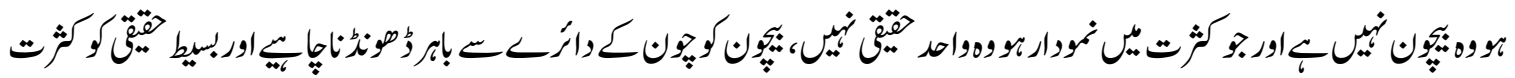

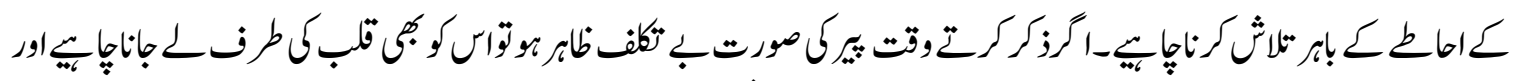

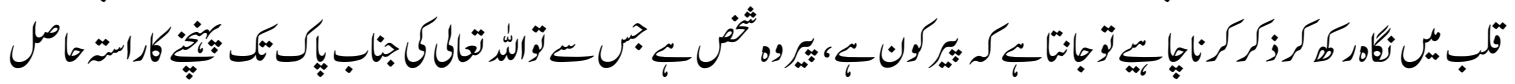

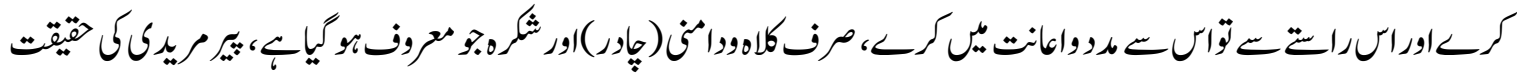

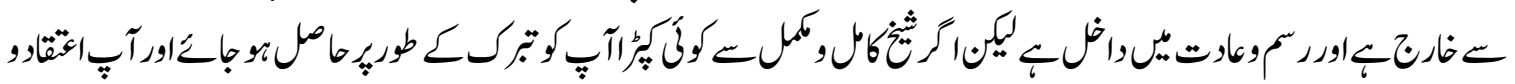

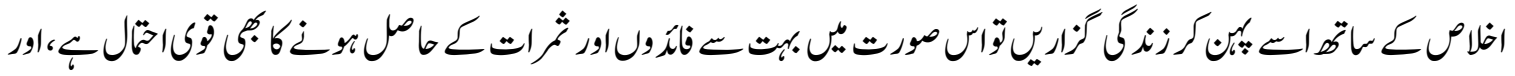

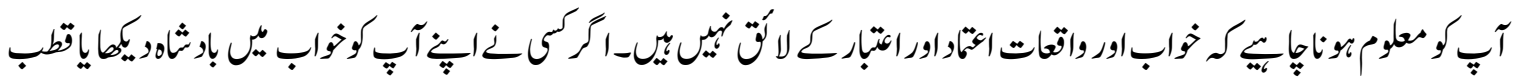

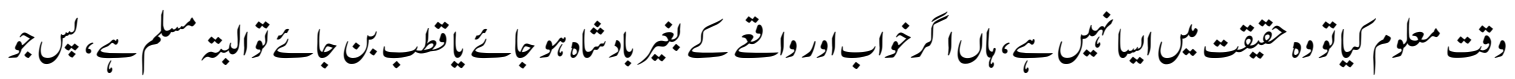

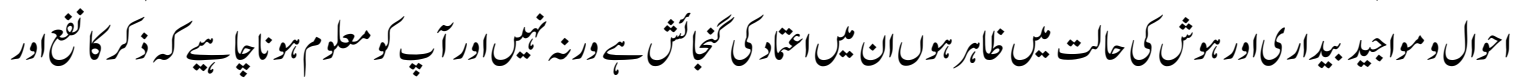




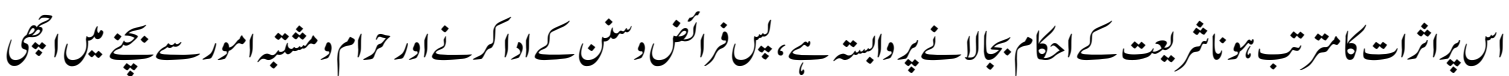

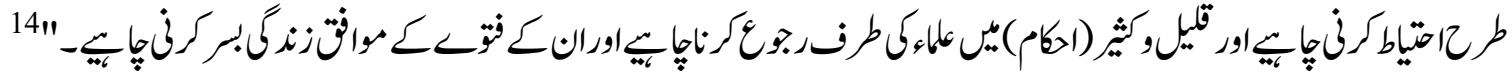

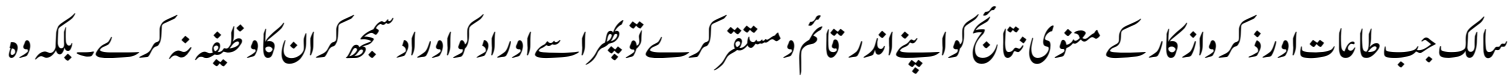

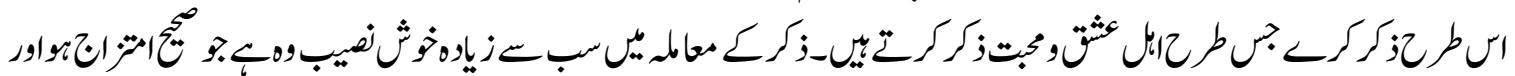

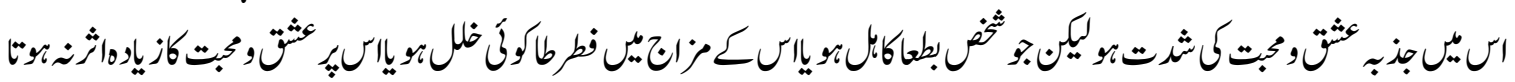

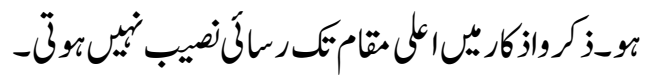

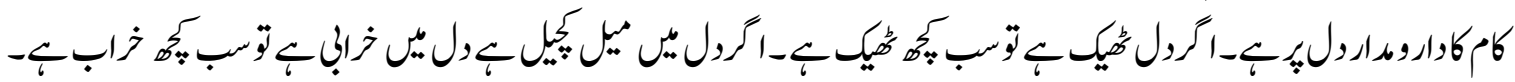

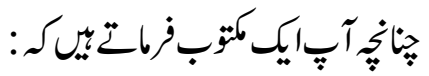

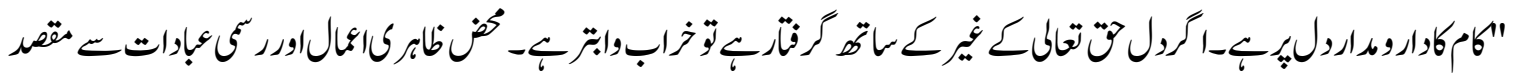

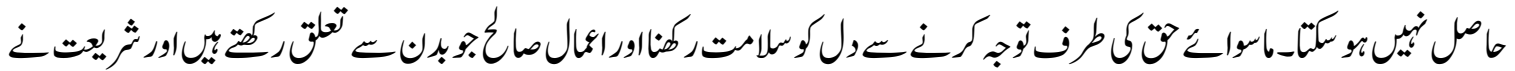

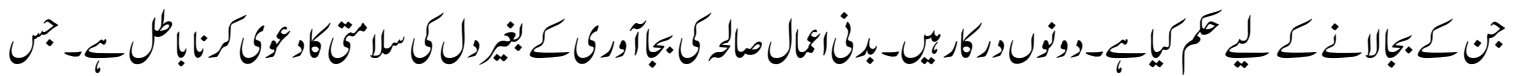

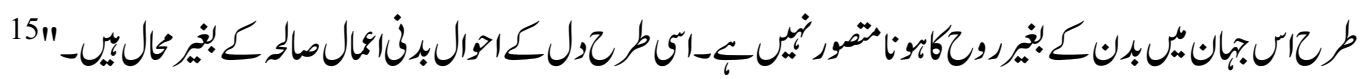

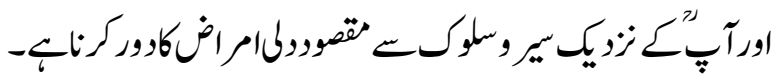

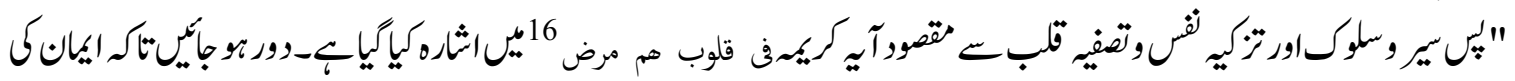

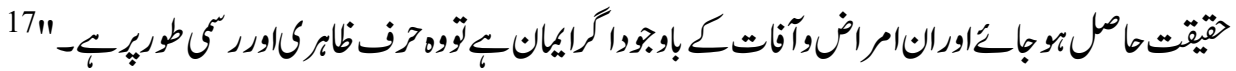

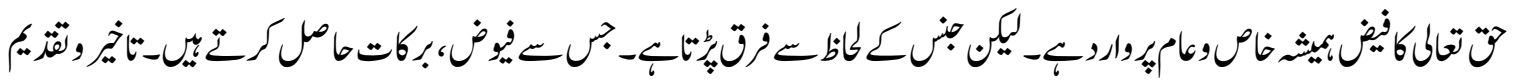

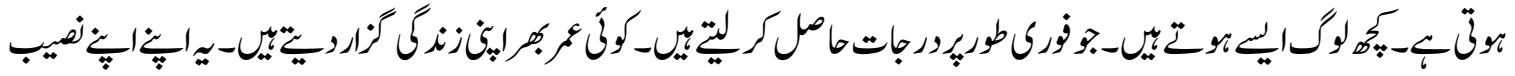

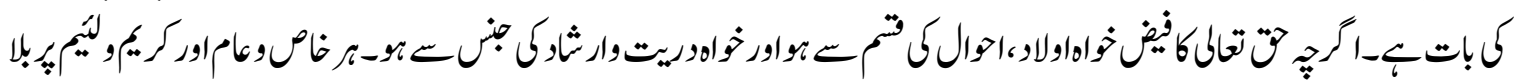

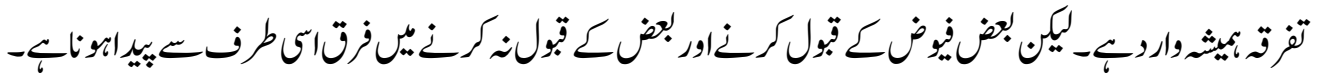
"وما ظلمهم الله ولكن انفسهم يظلمون"

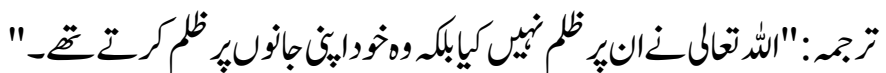

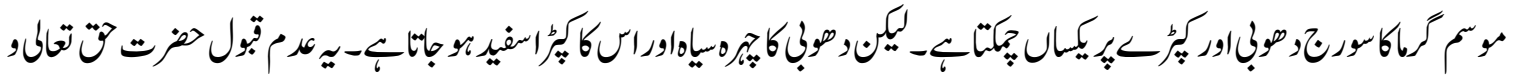

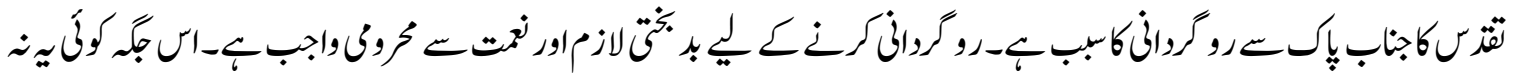

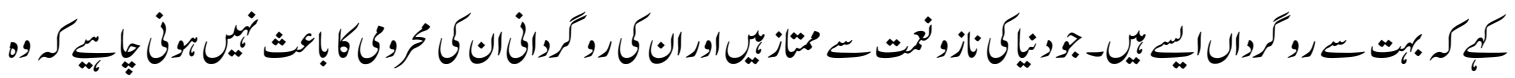

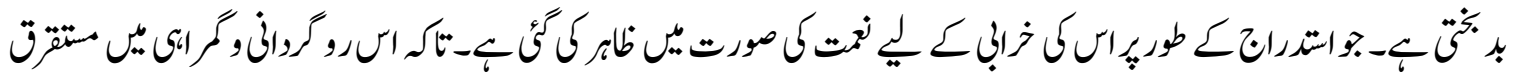

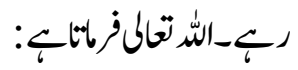


"ايكسبون انما نمدهم به من مال وبنين،نسارع لم فن الخيرت بل لا يشعرون"19

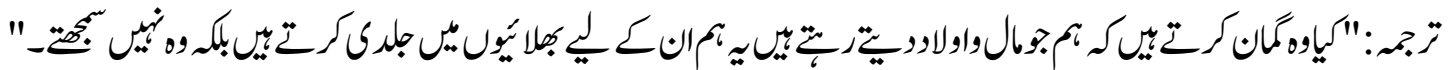

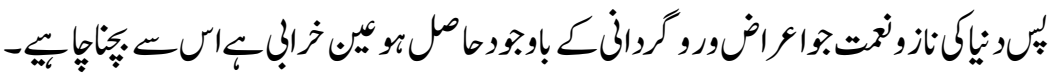

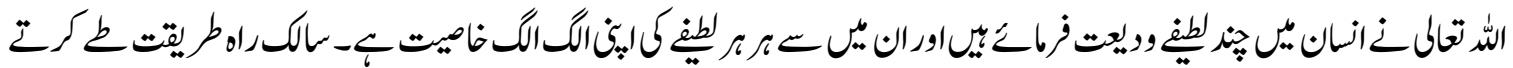

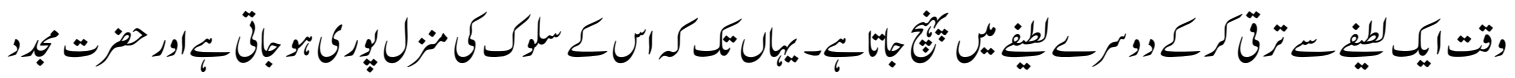

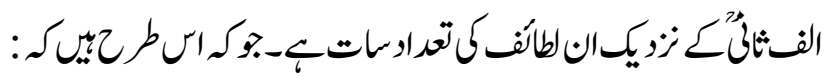

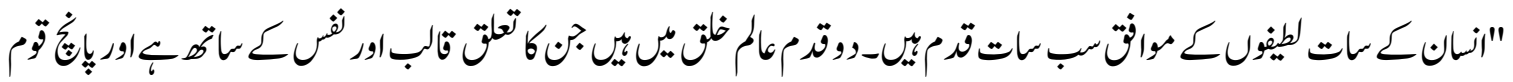

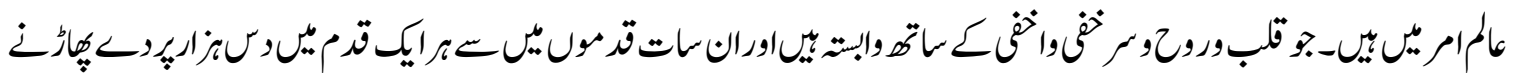

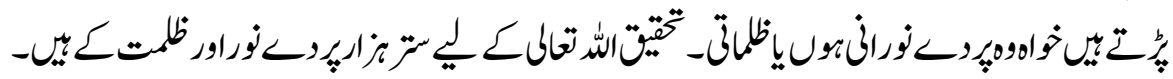

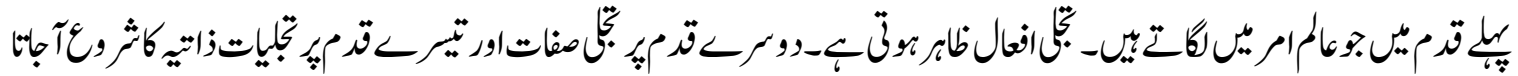

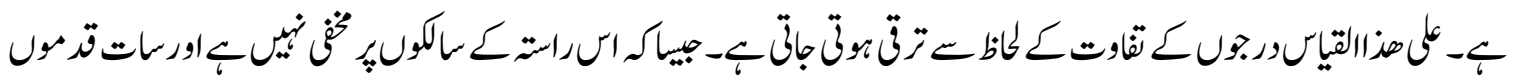

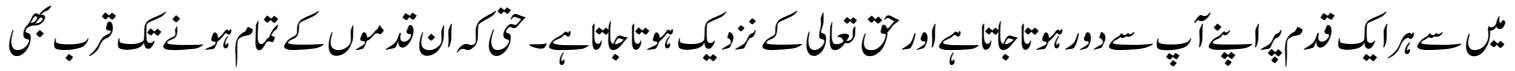

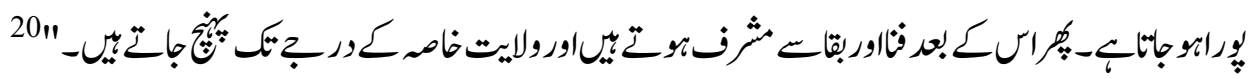

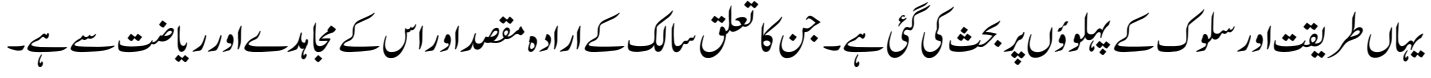

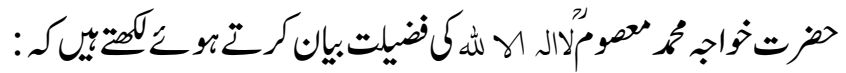

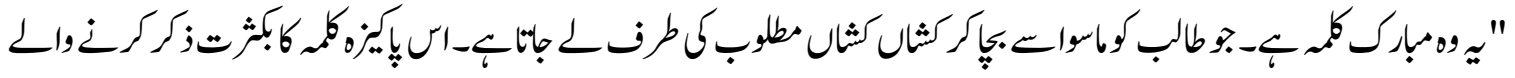

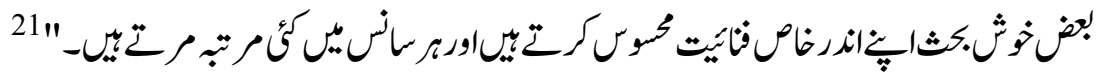

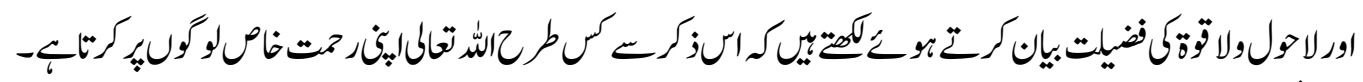

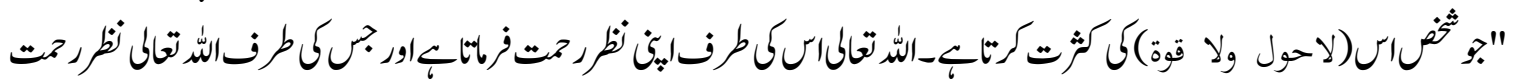

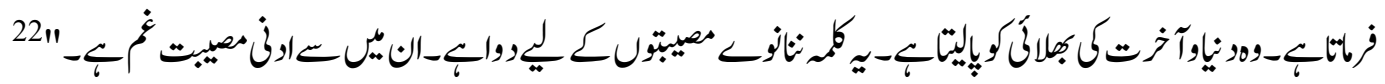

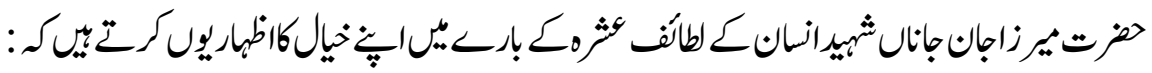

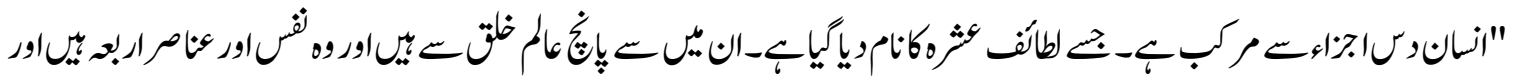

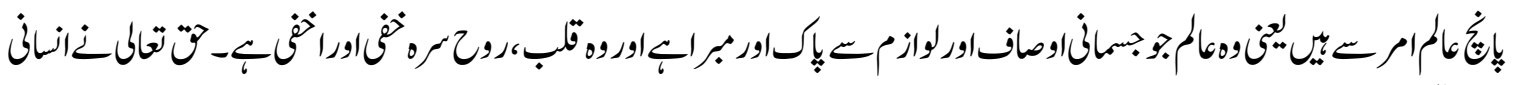

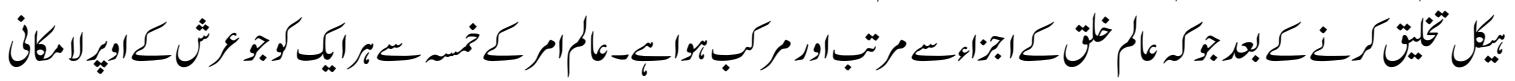

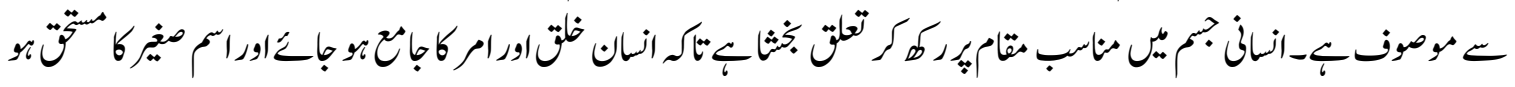




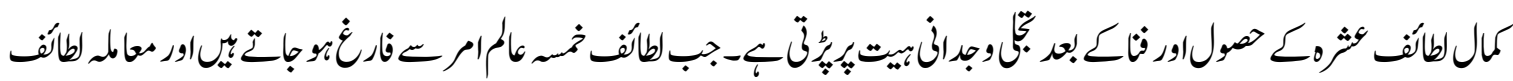

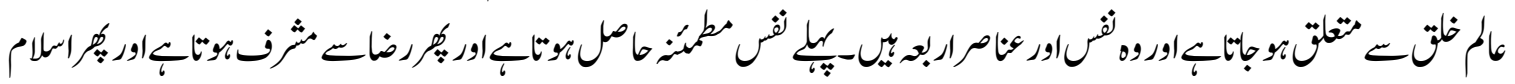

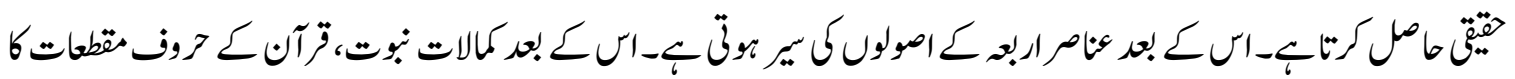

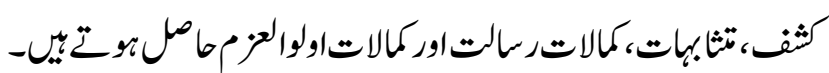

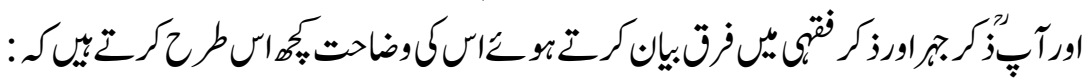

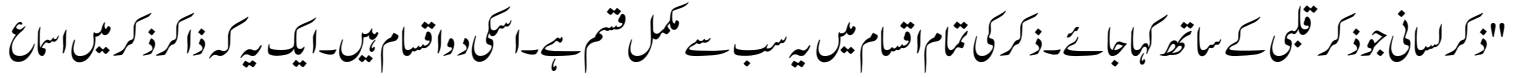

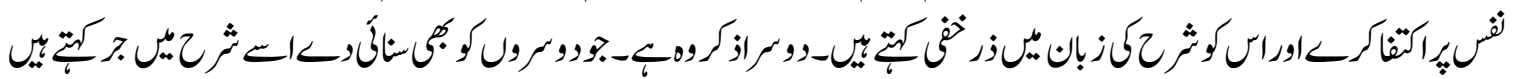

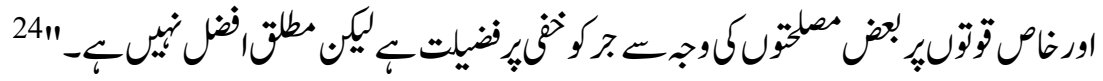

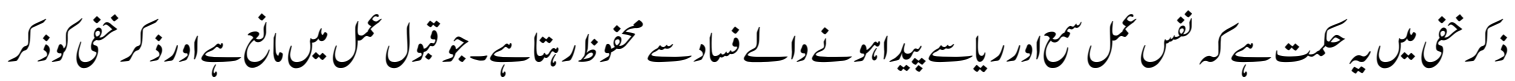

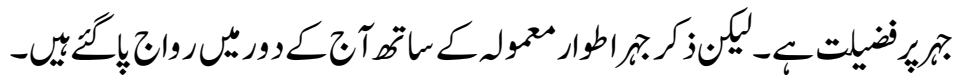

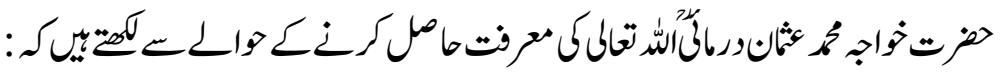

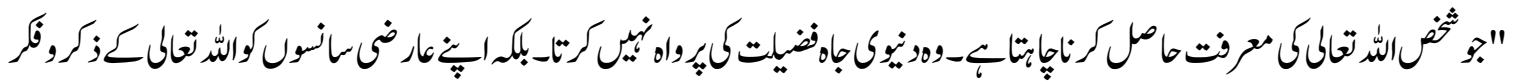

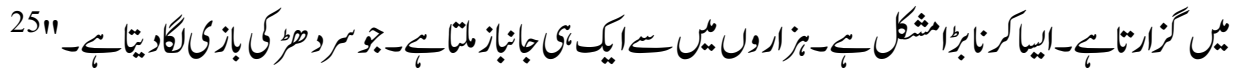

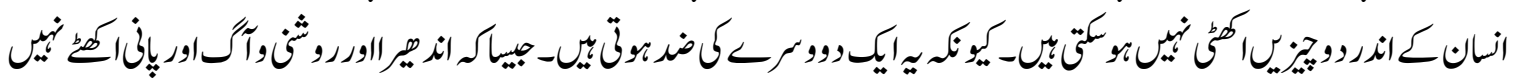

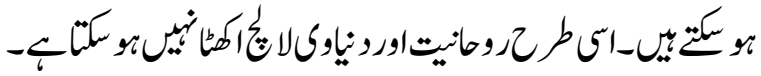

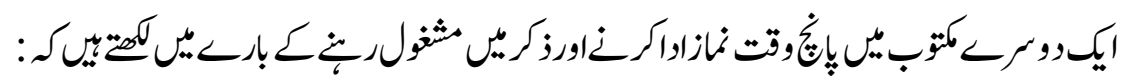

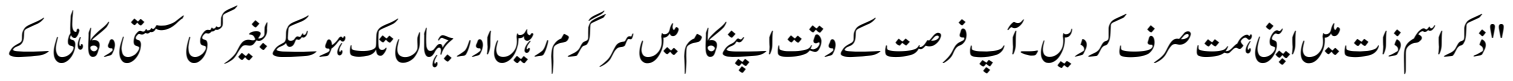

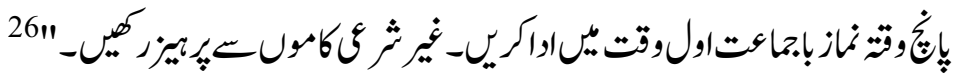

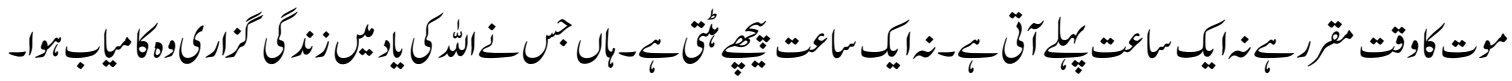

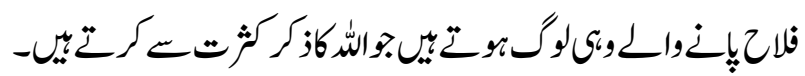

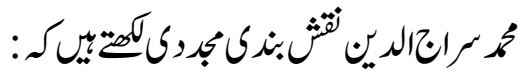

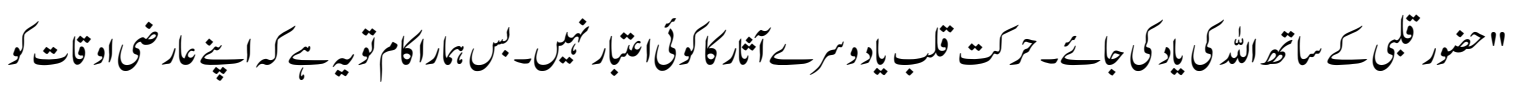

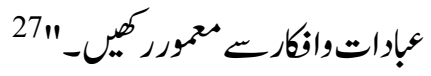

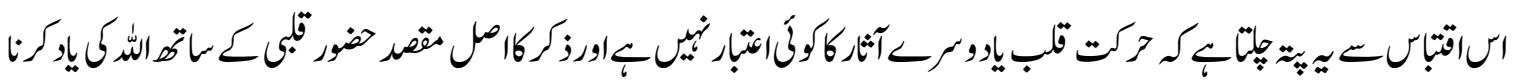

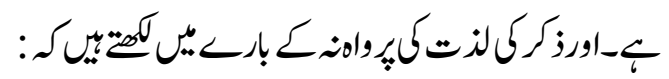

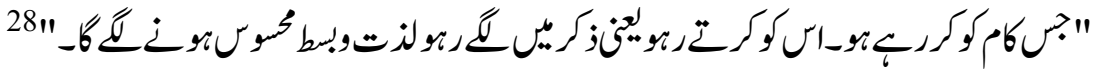




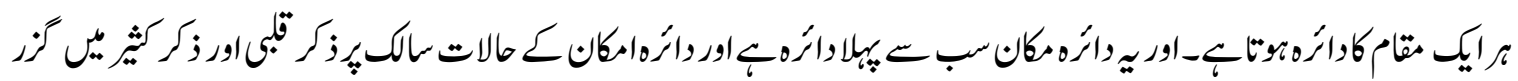

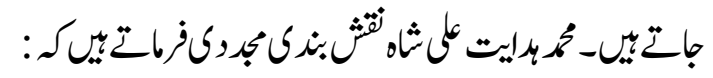

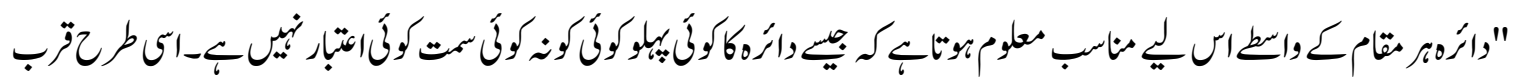

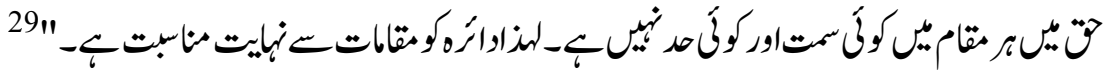

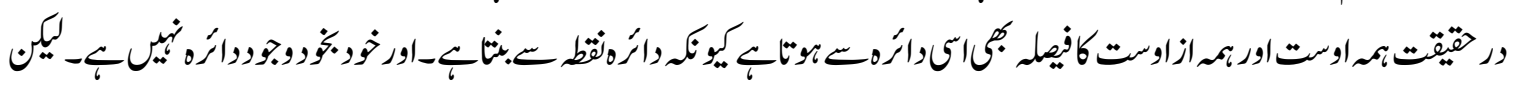

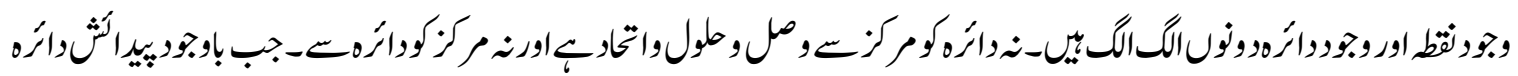

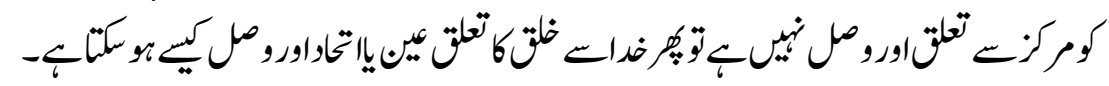
سلطانانزار:

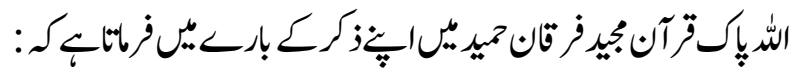
"الله واذكروا الله كثيرا لعلكم تفلحون"

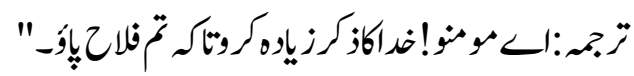

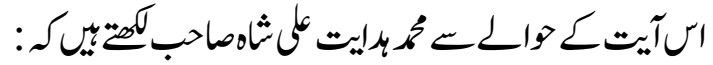

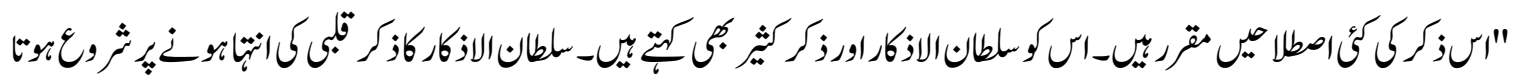
$31 "-\sum_{6}$

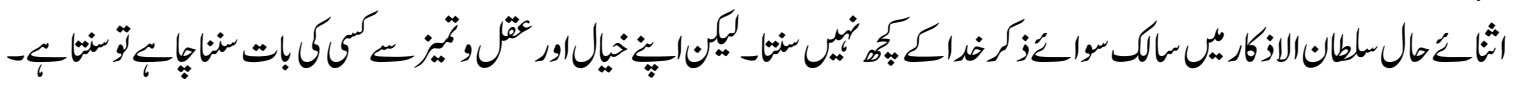

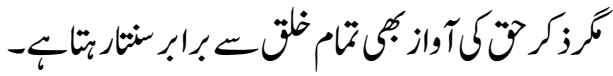

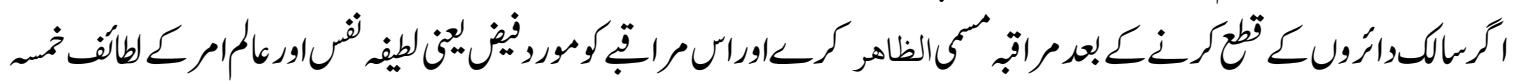

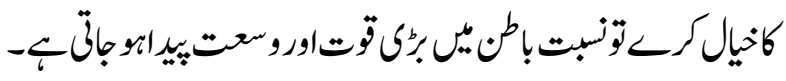

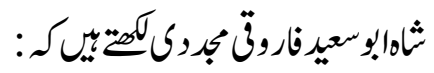

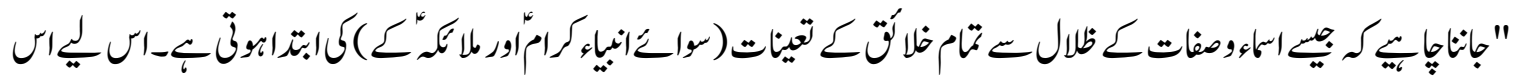

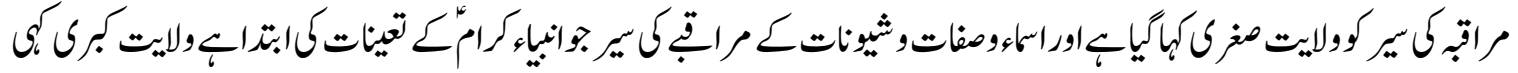

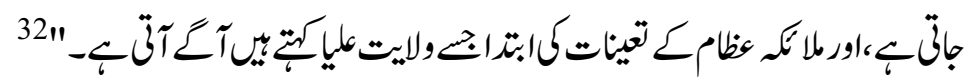

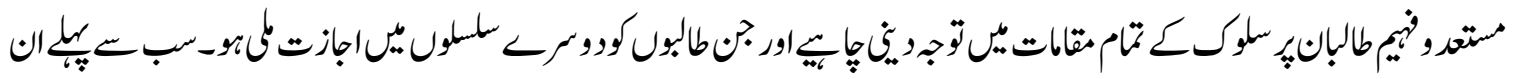

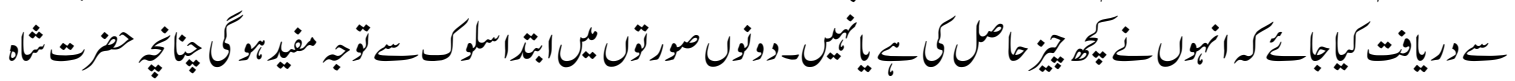

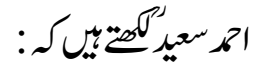

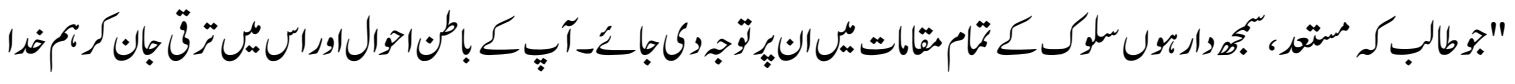




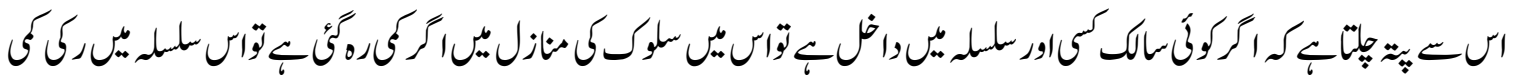

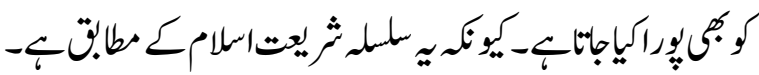

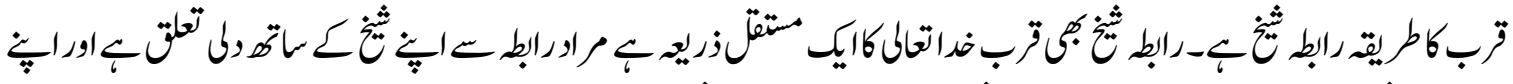

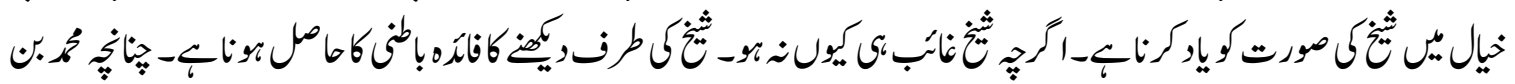

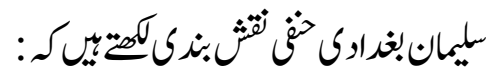

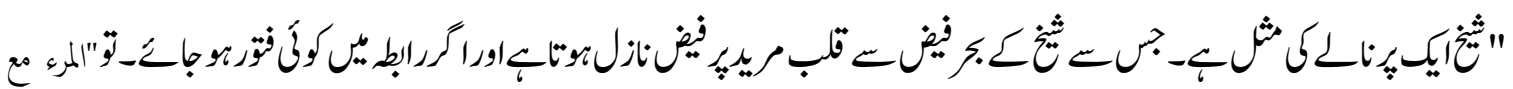

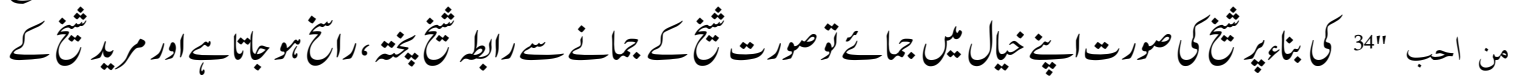

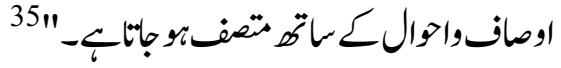

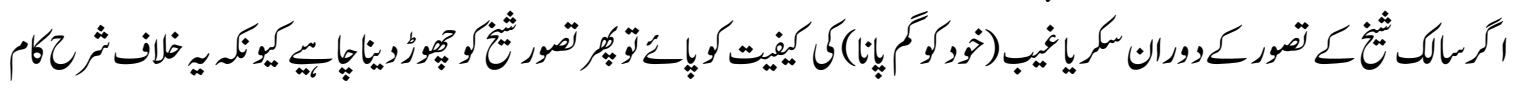

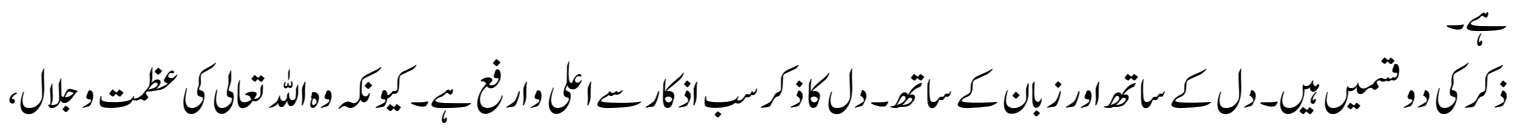

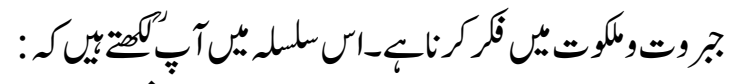

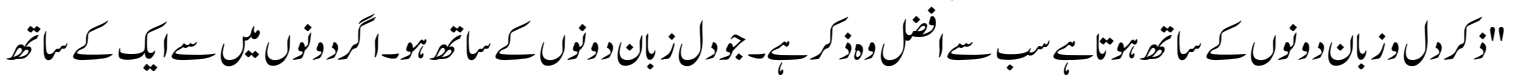

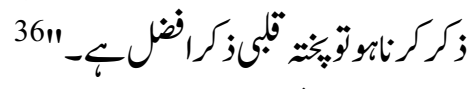

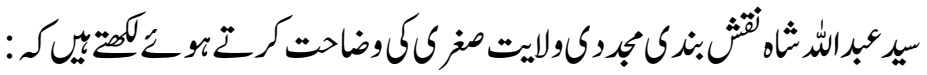

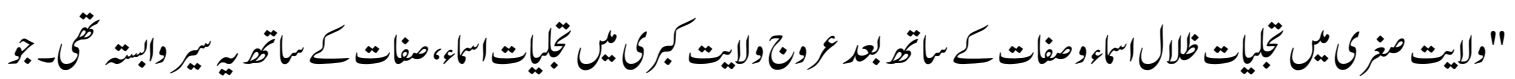

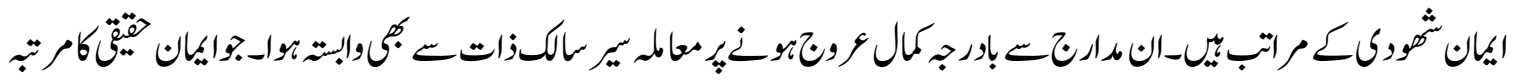

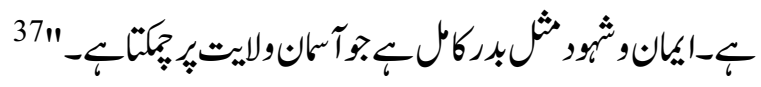

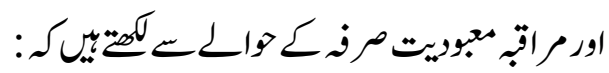

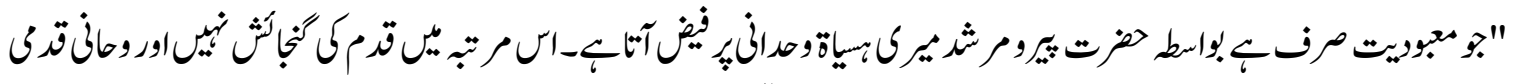

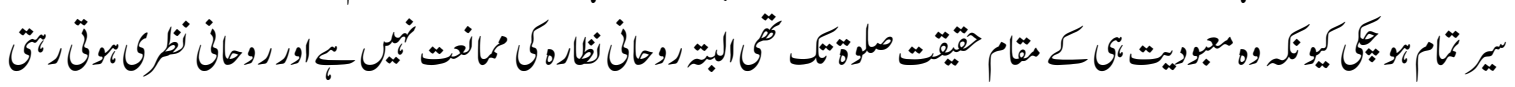
3811 $-6$

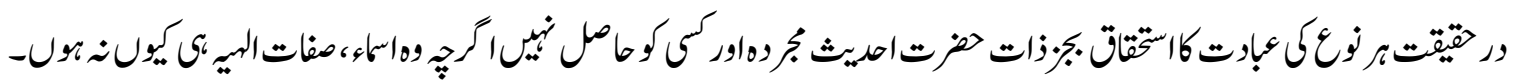

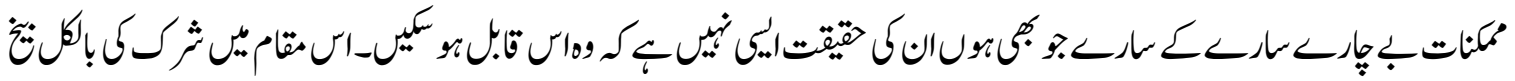
كن بوجاقة 


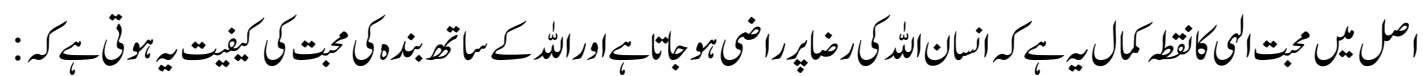
" تركم ركعا سجدا يتيغون فضلا من الله ورضوان"39

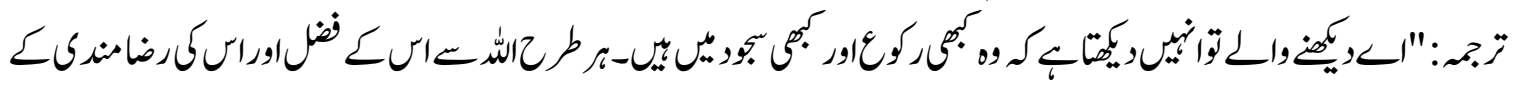

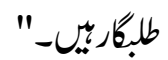

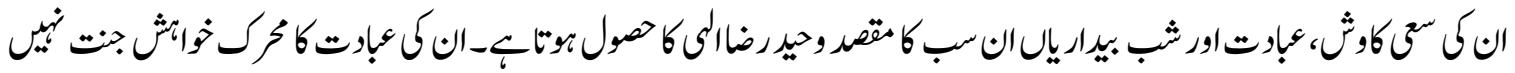

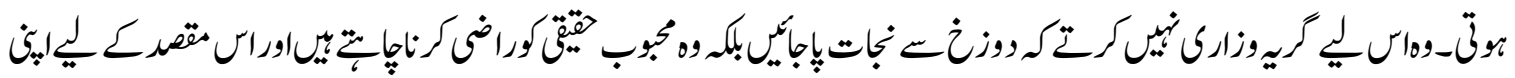

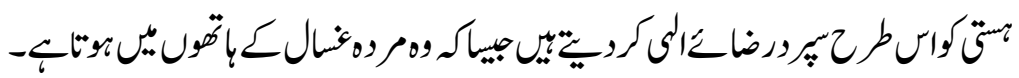

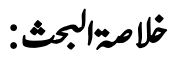

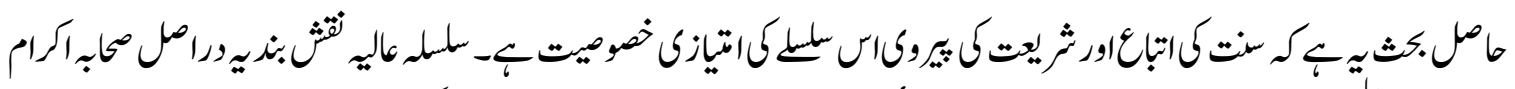

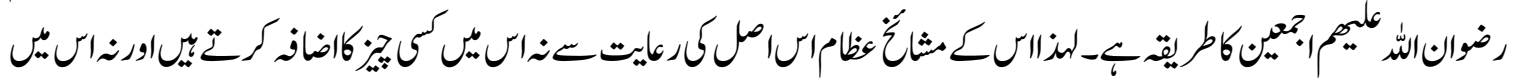

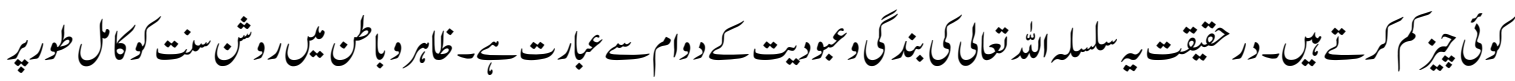

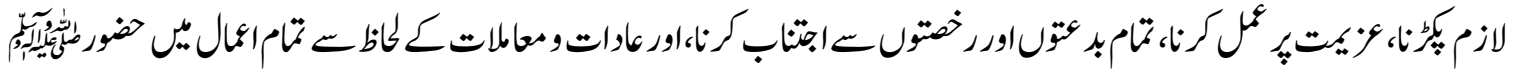

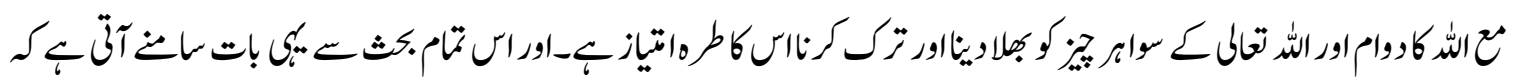

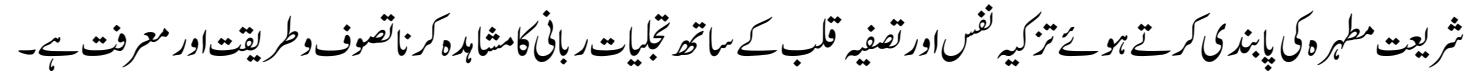
والرجات 35:5.5 1

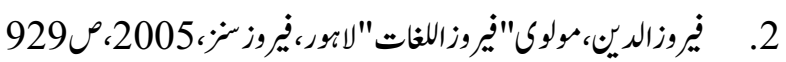
37:18.

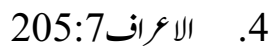

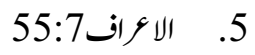
16-72. 6

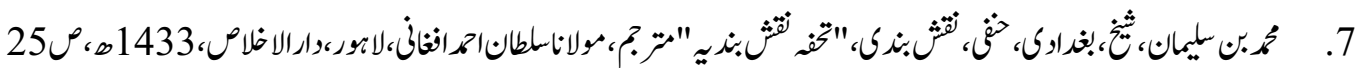
8.

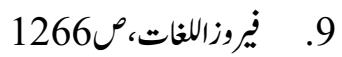

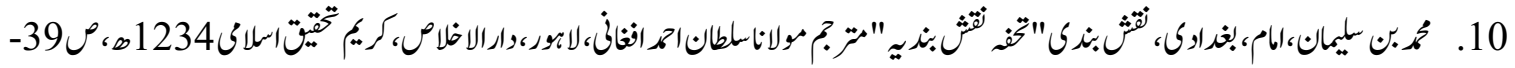

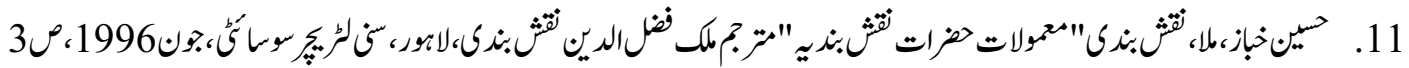

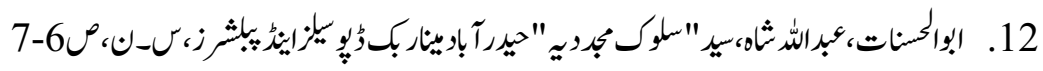




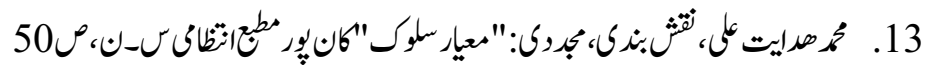

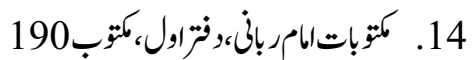

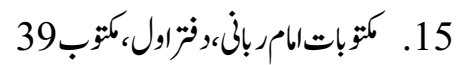

$$
\begin{aligned}
& \text { 16. 20:20 البر }
\end{aligned}
$$

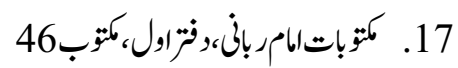

$$
\begin{aligned}
& \text { 18. 117:3 آل 18 }
\end{aligned}
$$

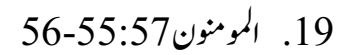

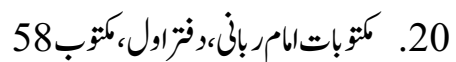

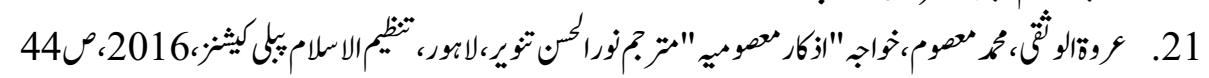

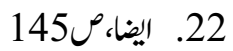

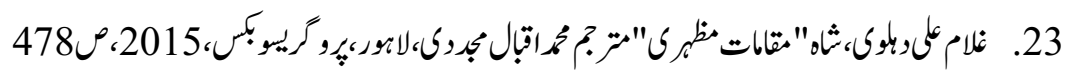

$$
\text { 24. اليضا، 252 }
$$

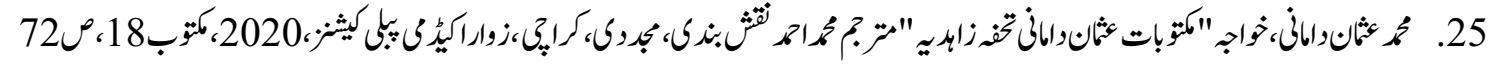

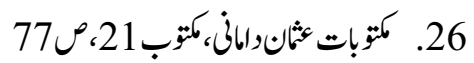

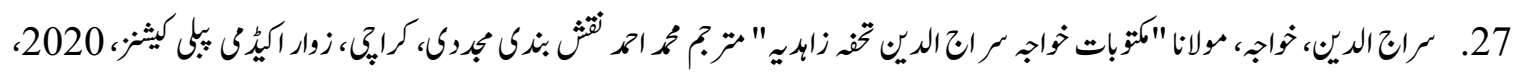

$$
\begin{aligned}
& \text { كتوب24، ص204 }
\end{aligned}
$$

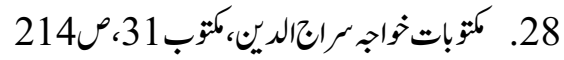

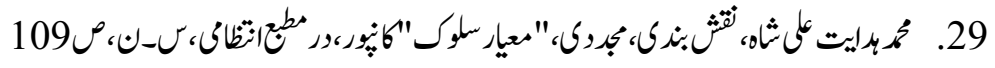

$$
\begin{aligned}
& \text { 62:10 30 }
\end{aligned}
$$

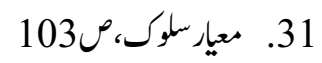

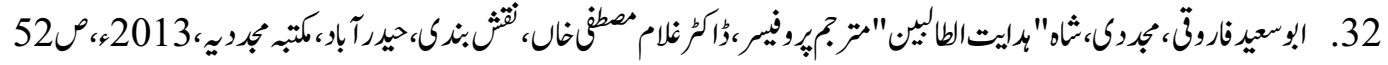

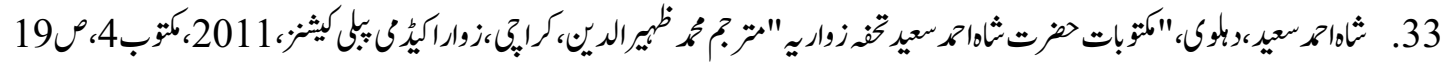

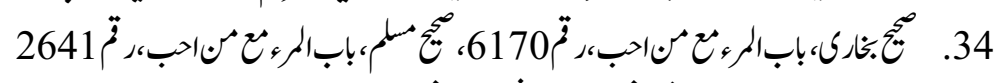

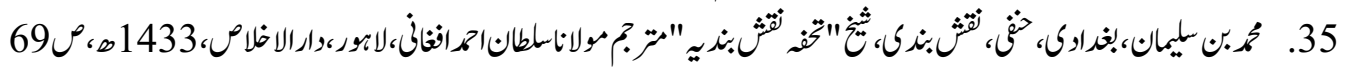

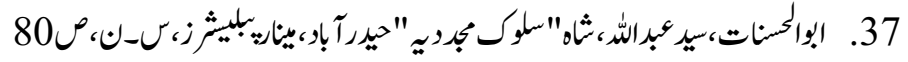

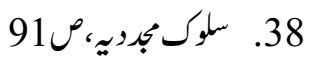

$$
\begin{aligned}
& \text { 29:48تُ 39 }
\end{aligned}
$$

\section{References}

1. Al Maidah: $35: 5$

2. Ferozudin, Molvi "Feroz Al Lughat", Lahore, Feroz Sans, 2005, p. 929.

3. Al Noor: $37: 18$ 
4. Al Aeraf: 205:7

5. Al Aeraf: 55:7

6. Al Jinn: $16: 72$

7. Muhammad bin Suleman, Shaikh, Baghdadi, Hanfi, Naqshbandi, "Tuhfa Naqshbandi" Mutarjum: Molana Sultan Ahmed Afghani, Lahore, 1433 AH, p. 25.

8. Feroz Al Lughat, p. 1437.

9. Feroz Al Lughat, p. 1266.

10. Muhammad bin Suleman, Shaikh, Baghdadi, Hanfi, Naqshbandi, "Tuhfa Naqshbandi" Mutarjum: Molana Sultan Ahmed Afghani, Lahore, 1234 AH, p.38-39.

11. Hussain Khabaz, Mula, Naqshbandi, "Mamolat Hazraat Naqshbandiya", Mutarjum: Malik Fazaluddin Naqshbandi, Lahore, Sani Literature Society, June 1996, p. 3.

12. Abu al Husnat, Abdullah Shah, Syed "Salook Mujadidya" Hyderabad Minar Book Depo Sales and Publisher, p. 6-7.

13. Muhammad Hidayat Ali, Naqshbandi, Mujadid, "Mayar Salook" Kanpur, Matba Intazami, p. 50.

14. Maktobat Imam Rabani, Daftar Awal, Maktoob 190.

15. Maktobat Imam Rabani, Daftar Awal, Maktoob 39.

16. Al Baqarah: 20:2.

17. Maktobat Imam Rabani, Daftar Awal, Maktoob 46.

18. Al Imran: $117: 3$.

19. Al Mouminoon: 55-56:57.

20. Maktobat Imam Rabani, Daftar Awal, Maktoob 58.

21. Urwat al Wasqi, Muhammad Masoom, Khuwaja "Azkar Masoomiya" Mutarjum: Noorul Hassan Tanveer, Lahore, Tanzeem Islam Publications, 2016, p. 44.

22. Ibid, p. 145.

23. Ghulam Ali Dehalvi, Shah, "Maqamat Mazhari" Mutarjum: Muhammad Iqbal Mujadadi, Lahore, Progressive Books, 2015, p. 478.

24. Ibid, p. 452.

25. Muhammad Usman Damani, Khuwaja "Maktoobat Usman Damani Tuhfa Zahidiya", Mutarjum: Muhammad Ahmad Naqshbandi, Mujadadi, Karachi, Zawar Academy Publications, 2020, Maktoob 18, p. 72.

26. Maktoobat Usman Damani, Maktoob 21, p. 77.

27. Sirajuddin, Khuwaja, Molana, "Maktoob Khuwaja Sirajuddin Tuhfa Zahidiya", Mutarjum: Muhammad Ahmad Naqshbandi, Mujadadi, Karachi, Zawar Academy Publications, 2020, Maktoob 24, p. 204.

28. Maktoob Khuwaja Sirajuddin, Maktoob 31, p. 214.

29. Muhammad Hidayat Ali, Naqshbandi, Mujadid, "Mayar Salook" Kanpur, Matba Intazami, p. 109.

30. Al Juma: 62:10.

31. Mayar Salook, p. 103.

32. Abu Saeed Farooqui, Mujadadi, Shah "Hidayat ul Talibeen", Mutarjum: Professor Ghulam Mustafa Khan, Naqshbandi, Hyderabad Maktaba Mujadidya, 2013, p. 52.

33. Shah Ahmed Saeed, Dehalvi, "Maktoobat Hazrat Shah Ahmed Saeed Tuhfa Zawariya", Mutarjum: Muhammad Zahiruddin, Karachi, Zawar Academy Publications, 2011, Maktoob 4, p. 19.

34. Saheeh Bukhari, hadith: 6170, Saheeh Muslim, Hadith; 2641.

35. Muhammad bin Suleman, Shaikh, Baghdadi, Hanfi, Naqshbandi, "Tuhfa Naqshbandi" Mutarjum: Molana Sultan Ahmed Afghani, Lahore, 1433 AH, p. 69.

36. Ibid, p. 77.

37. Abu al Husnat, Abdullah Shah, Syed "Salook Mujadidya" Hyderabad Minar Book Depo Sales and Publisher, p. 80.

38. Salook Mujadidya, p. 91.

39. Al Fatah: $48: 29$. 